\title{
Cross-cultural adaptation to Brazilian Portuguese of the Michigan Neuropathy Screening Instrument: MNSI-Brazil
}

\author{
Adaptação transcultural para o português brasileiro do Michigan Neuropathy Screening \\ Instrument: MNSI-Brasil \\ Franassis Barbosa de Oliveira1,2,4, Kárenn Klycia Pereira Botelho², Arthur Rodrigues Bezerra ${ }^{1,3}$, Diego lgor de \\ Oliveira Azevedo ${ }^{1,3}$, Clarissa Cardoso dos Santos-Couto-Paz ${ }^{1,3}$, Emerson Fachin-Martins ${ }^{1,3}$
}

\begin{abstract}
Since 1994, the University of Michigan Diabetes Research and Training Center proposed an instrument to measure neuropathies not yet adapted to use in Brazil. Then, this study aimed to adapt cross-culturally the Michigan Neuropathy Screening Instrument (MNSI) into Brazilian Portuguese, verifying its reliability. Thirty diabetic patients were initially evaluated with the adapted version after completed the essential steps to accomplish the cross-cultural adaptation. Twenty-two of them completed the procedures to repeat the measured scores after day 1 (trial 0 ). The repeated measurements were tested at days 2 or 3 (trial 1) by another rater (inter-rater reliability) and retested at day 20 (trial 2) by one of the attended raters (inter-test reliability). There were not great semantics, linguistics or cultural differences between two versions and excellent reliability was confirmed by intra-class correlation coefficient above 0.840. It was concluded that MNSI in the Brazilian version is reliable and it is ready to use.
\end{abstract}

Keywords: diagnosis; monitoring; diabetic neuropathies.

\section{RESUMO}

Desde 1994, o Centro de Treinamento e Pesquisa em Diabetes da Universidade de Michigan propôs um instrumento não ainda adaptado para uso no Brasil para mensurar neuropatias. O objetivo deste estudo foi adaptar transculturalmente o Michigan Neuropathy Screening Instrument (MNSI) para o Português brasileiro, verificando sua confiabilidade. Trinta pacientes diabéticos foram inicialmente avaliados pela versão adaptada depois de completados os passos essenciais para finalizar a adaptação transcultural. Vinte e dois deles completaram os procedimentos para repetir os escores medidos depois do dia 1 (ensaio 0). As medidas repetidas foram testadas nos dias 2 ou 3 (ensaio 1) por outro examinador (confiabilidade interexaminador) e retestadas no dia 20 (ensaio 2) por um dos examinadores participantes (confiabilidade interteste). Não existiam diferenças semânticas, linguísticas ou culturais entre as duas versões e excelente confiabilidade foi confirmada pelo coeficiente de correlação intra-classe acima de 0,840. Conclui-se que o MNSI na versão brasileira é confiável e está pronto para uso.

Palavras-chave: diagnóstico; monitoramento; neuropatias diabéticas.

Diabetic sensorimotor polyneuropathy (DSPN) affects approximately $10 \%$ of the subjects newly diagnosed ${ }^{1,2,3}$ as type 2 diabetes and this percentage can increase by duration, lack of glycemic and cardiovascular complications ${ }^{3,4,5}$. When appropriately treated by restoration of glycemic control $^{3}$, the progression of the DSPN can be delayed and the diabetic ulcers and amputations reduced ${ }^{3,6}$. However, the neuropathy is still the major cause of diabetic foot presenting damaged nerve fibers and this secondary complication affects more than $50 \%$ among the subjects diagnosed

1Universidade de Brasília, Faculdade de Ceilândia, Programa de Pós-Graduação em Ciências e Tecnologias em Saúde, Brasília DF, Brasil; Universidade Estadual de Goiás, Escola Superior de Educação Física e Fisioterapia, Departamento de Fisioterapia, Goiânia Go, Brasil;

${ }^{3}$ Universidade de Brasília, Faculdade de Ceilândia, Fisioterapia, Brasília DF, Brasil;

¿Universidade de Brasília, Programa de Pós-Graduação em Ciências e Tecnologias em Saúde, Brasília DF, Brasil.

Correspondence: Emerson Fachin-Martins; Campus de Ceilândia, Centro Metropolitano; Conjunto A, Lote 01; $72220-275$ Brasília DF, Brasil; E-mail:efmartins@unb.br

Conflict of interest: There is no conflict of interest to declare.

Support: Fundação de Amparo à Pesquisa do Estado de Goiás e Coordenação de Aperfeiçoamento de Pessoal de Nivel Superior (FAPEG/CAPES). Grant: Programa Pesquisador Visitante Especial (PVE) da Coordenação de Aperfeiçoamento de Pessoal de Nivel Superior (CAPES), Processo: 88881.068134/2014-01, Proposta: 300665.

Received 31 October 2015; Received in final form 07 January 2016; Accepted 16 May 2016 
from long time, despite could be appreciated that DSPN does not surspass the $10 \%$ hallmark?

Different guidelines recommend annual evalutation for DSPN and clinical examination of the lower extremities and feet in subjects with diabetes, representing a significant burden for basic care services whereas primary prevention ${ }^{1,2,8}$.

Regularly, the gold standard methods to diagnose DSPN, e.g. nerve condution studies, do not are always easily avalible due the high cost, especially in Brazil ${ }^{7}$. Given that, the Michigan Neuropathy Screening Instrument (MNSI) has been described as an alternative low cost method by fast application which allows to score, classify and diagnose the neuropathy9.

Developed at Michigan Diabetes Research and Training Center in the United States, the MNSI aims to screen the symmetric diabetic neuropathy from individuals with diabetes mellitus and its reliability and acuracy were discussed in previous studies ${ }^{910,11}$, but not for Brazilian population.

Also available to screen peripheral neuropathy, the Pain Quality Assessment Scale (PQAS) were cross-adapted for Brazilian Portuguese; however the PQAS was designed to focus on assessing the quality of the neuropathic pain in cancer patients ${ }^{12}$. Due to the specific approach to DSPN that includes other issues related to peripheral neuropathy apart from neuropathic pain, the MNSI could be considered a better scale to be used in the diabetic population.

Given the circumstances and once authorized by the MNSI creators, this study aimed to adapt cross-culturally the MNSI into Brazilian Portuguese, verifing its reliability.

\section{METHOD}

In order to ensure the quality of the adapted tool, we carried out a cross-sectional study to translate and adapt transculturally the MNSI, called by us MNSI-Brazil. The essential steps to accomplish our aim was guided by the process to adapt transculturally self-report measures published by Beaton and collaborators ${ }^{13}$ in five sequential stages: 1) translation, 2) synthesis, 3) back translation, 4) expert committee review and 5) pretesting, accompanied paralelly by the transversal stage of submission and appraisal of all written reports by developers.

This guideline refers to international rules established to secure the equivalence maintenance between the original questionnaire version and the destiny, in this case: the Brazilian population. Once finished, the MNSI-Brazil was submitted to psychometric testing to verify the inter-rater and inter-test reliabilities.

This study was approved by Fundação de Ensino e Pesquisa em Ciências da Saúde (FEPECS) Ethics Committee, D.C. (Report 160.752/2012) and all the participants signed a term of free and enligthened acceptance and they were informed about the procedures of all the stages in the study.

\section{The Michigan Neuropathy Screening Instrument}

The original version of MNSI was created in the Michigan Center for Diabetes Translational Research (MCDTR) and the authorization to performe the cross-cultural adaptation was given by Pamela A. Campell as requested by e-mail sent May 21, 2013 and answered May 22, 2013.

The instrument is composed by an introduction which gives guidance on how to use MNSI, followed by two application forms where one of them is self-administered by the patient. The first one, the self-administred, has been prepared to score the clinical history (history questionnaire) and the second one to score physical assessment. Afterward, the individual scores are added up to give a total value. Total value larger than 8 suggests a symmetrical peripheral neuropathy.

\section{Translation}

All parts of the original MNSI (including the introduction) were translated into Brazilian Portuguese by two native Brazilian Portuguese speakers who worked independently. They were fluent in English language and have different profiles and academic education areas (physical therapy and engeneering). One of them was the "ingenuous" translator, because he did not have experience in the health science. The used "ingenuous" strategy obtains a translation which reflects the linguistic norms practiced by population without be influenced by schoolar formality.

\section{Synthesis}

In order to prepare the first Brazilian Portuguese version, the authors compared and synthesized the two translations by consensus. The two translations were consistent in almost its totality. Only three text fragments (words or phrases) chosen by each translator were different, however expressing the same meaning from the Brazilian Portuguese lexicon. At the end, they were defined by consensual decision made by the authors in: 1) "classificação" instead of "triage", 2) "perguntas sobre a sensibilidade de suas pernas e pés instead of questões sobre a sensiblidade de suas pernas e pés" e 3) "hálux" instead of "dedo grande do pé".

\section{Back translation}

The first Brazilian Portuguese version was back translated into English by two professional bilingual translators who were fluent in Portuguese and English. They did not participate in the previous stage and did not know the MNSI.

Following, the two back translated versions were compared with the original MNSI to validate the consistence in the translated version which reflected the same original meaning. The two back translations were very similar with just two differents text fragments. As in the synthesis, by consensual decision were defined: 1) "Michigan Neuropathy Screening Instrument" instead of "Michigan Neuropathy Classification Instrument" and 2) "numb" instead of "asleep". 


\section{Expert committee review}

A committee composed by 3 rehabilitation and health specialists, bilingual, was assisted by the first author to achieve cross-cultural equivalence and consolidate all the versions of the questionnaire and develop what was considered the prefinal version for field testing.

Committee's meetings were regularly performed to seek the linguistic equivalence necessary to make the prefinal version ${ }^{13}$. The words julged do not be equivalent by one of the members and text adaptations were reviewed and discussed to reach agreement on the preliminary version applied to Brazilian population.

\section{Pretesting}

The prefinal version (Appendix 1, 2 and 3) of the MNSIBrazil was applied in 30 subjects with diabetes mellitus and tested to assure cross-cultural equivalence. During the pretesting, we did not find words of which Brazilian attendee could not understand. So the MNSI-Brazil final version did not change from de prefinal version.

The 30 subjects presenting clinical diagnosis of type 2 diabetes mellitus were evaluated by MNSI-Brazil. The sample was formed by convenience from two health services: 1) an assistential program called Universidade Aberta à Terceira Idade (UNATI) linked to the Universidade Estadual de Goiás (UEG) located in Goiânia, Goiás, Brazil and 2) a Center Health Service (CHS) called CHS number 3, located in the Ceilândia Administrative Area, Distrito Federal, Brazil.

Participants presenting peripheral or central neurological-related illness do not associated with diabetes in the medical records (e.g. traumatic injuries, infections, inherited causes and exposure to toxins) and those ones with cognitive problems identified by Mini-Mental State Examination (MMSE) were excluded. Depending the scholar level, we consider different scores as MMSE cut-off point as recommended. The 13, 18 and 26 scores respectively for those not able to read and write, for those attending at least 7 years of scholling and those schooling 8 years or more ${ }^{14,15}$. In order to give general antropometric characteristics of the sample, we included information about body composition (body mass index) and skin color (leucoderm, faioderm and melanoderm).

The MNSI-Brazil was applied in an acclimatized room where the volunteeers were confortably accommodated to aswer the questions put by the raters who filled out the instrument.

They spended the time required and the raters were oriented to take notes from dubious words or unclear answer. The time performed to apply the MNSI-Brazil was timed by each rater and all participators. At the end, the participants were questioned about their difficulties. The pretesting was conducted from August 2014 to May 2015.

\section{Inter-rater and inter-test reliability}

A group composed by 22 volunteers among the initial sample $(n=30)$ agreed to take part in the reliability tests. The tests were performed in three times (trial 0, 1 and 2), during four different days (day 1, days 2 or 3 and day 20), by two different raters: rater 1 and 2 . The 30 initial volunteers completed the first MNSI-Brazil application oriented by the rater 1. In the day 2 or 3,22 among them repeat the test applied by other rater to test the inter-rater reliability. Twenty days after the test, the rater 1 retested the 22 volunteers.

The inter-rater reliability was verified during the test phase comparing the MNSI-Brazil scores took in the trial 0 (day 1 ) and trial 1 (days 2 or 3). The trials 0 and 1 was performed by different raters (they performed blind-independent assessments). In turn to verify inter-test reliability, the scores obtained in the trial 0 (day 1 ) were compared to those same scores took during trial 2 (day 20) by the rater 1 . After 20 days is few probable to find peripheral nerve degeneration with visible clinical evaluation and it is a good period to confirme inter-test repeatability ${ }^{16}$.

\section{Data processing and statistical analysis}

The Shapiro Wilk normality test was used to verify whether the variables demonstrated the Gaussian distribution and it determined the need for parametric tests in the analysis. The significance level for all analyses was established at alfa equal 0.05. We use descriptive statistic to characterize the sample used to reliability tests by mean of average, standart deviation (SD) and frequency distribution (absolut and relative).

The Intra-class Correlation Coefficient (ICC) and the Limits of Agreement (LOA) were used to define the respective quality and magnitude of inter-rater and test-retest reliability, which were plotted with a $95 \%$ confidence interval (CI) using the Bland Altman method. ICC values above 0.75 , between 0.40 and 0.75 and below 0.40 represented excellent, moderate and poor reliabilities respectively ${ }^{17}$.

\section{RESULTS}

\section{Translation and cross-cultural adaptation}

We identify few semantic, linguistic or cultural diferences during the process of MNSI translation and none serious discrepancies about the vocabulary. Those few divergent words and adaptation in the text were elucidated and eliminated by the expert committee review. The same occurred in the back translation stage. During the pretesting, all questions were appropriately answered and comprehended for the totality of the participants.

During the translation stage, between the versions made by the two translators, we do not found divergencies, but rather synonym words. Then, this point was solved choosing the more common synonymous used by Brazilian people.

In the same way, the back translation presented few divergencies between the two versions made by each English language native translators and the choice was done by the terms used in the original version. 


\section{Reliability tests}

The measurement conditions were defined by the raters who tested (rater 1 and 2) the volunteers and by the moment when the measurements were obtained (test and retest), establishing two mensurement conditions to test inter-rater and inter-test reliabitily.

The participants were $69.05 \pm 7.59$ years old (mean \pm standard deviation), within the overweight range defined by adult Body Mass Index (BMI) classification (28.56 \pm 4.05$)$. All participants were presenting adequated cognitive status scored evaluated by MMSE in $26.55 \pm 3.17$ and verified during the tests by the full comprehension of the self-administered part of the MNSI-Brazil. All participants were able to read and write $(36 \%$ attending at least 7 years of scholling and $64 \%$ schooling 8 years or more).

The sample retested was predominantly female (95\%) and composed by leucoderm, faioderm and melanoderm people as established by Edgard Roquette Pinto who proposed a system to classify the three main categories based in the skin color and present in the Brazilian population (Table) ${ }^{12}$. The time spent to apply the self-administered part of the MNSIBrazil was around three minutes.

The average measured by the MNSI-Brazil in the 3 measurement conditions (rater 1 , rater 2 and retest) was $4.21 \pm 2.09$, ranging from 0 to 8 total scores. Just two subjects were scored 8 or more defining a diagnosis suggestion of DSPN. In the first measurement condition (rater 1) one subject had been scored 8 (DSPN diagnosis suggestion), however the dignosis was not suggested by the rater 2 and in the retest. Otherwise, the other subject who was scored 7 by the rater 1 was scored 8 by the rater 2 and retested confirming the diagnosis suggestion of DSPN.

The analysis of the inter-rater and inter-test reliability (Figure) obtained by the difference (Bland Altman method) and ICC values calculated from measurements taken by each

Table. Characteristics of the group submitted to reliability tests.

\begin{tabular}{lcc}
\hline Variables & Average or $\mathrm{n}$ & $\mathrm{SD}$ or $\%$ \\
\hline Quantitative & & \\
Age (years old) & 69.05 & \pm 7.59 \\
BMI & 28.56 & \pm 4.05 \\
Mini-mental (score) & 26.55 & \pm 3.17 \\
MNSI-Brazil (rater 1) & 4.36 & \pm 2.15 \\
MNSI-Brazil (rater 2) & 4.22 & \pm 2.24 \\
MNSI-Brazil (retest) & 4.04 & \pm 1.96 \\
Qualitative & & \\
Men & 1 & $5 \%$ \\
Women & 21 & $95 \%$ \\
Faioderm & 11 & $50 \%$ \\
Leucoderm & 6 & $27 \%$ \\
Melanoderm & 5 & $23 \%$ \\
Group from the total sample $(n=30)$ & 22 & $100 \%$ \\
\hline
\end{tabular}

Quantitative variables are presented in mean \pm standard deviation (SD) and qualitative variables are in absolut (n) and relative (\%) frequency distribution. BMI: Body Mass Index; MNSI: Michigan Neuropathy Screening Instrument. rater $(\mathrm{ICC}=0.840)$ and in each test $(0.864)$ respectively indicated excellent repeatability ${ }^{17}$. The Bland Altman plots detected mean differences between raters and tests showing small or no significant deviations from zero for most of the subjects. In general, the $95 \%$ LOA that was obtained between the different measures ranged from -2 to 2 points (upper and lower graphs in the Figure).

\section{DISCUSSION}

To date, none cross-cultural adaptation had been done to the MNSI. Then, aside from the newness to introduce a Portuguese version of this clinical tool, this study tested the reliability of the measuments obtained from this diagnosis method in the Brazilian population with diabetes mellitus. The cross-cultural adaptation avoids multinational and multicultural diversity to uniformize the concepts and evaluation aspects desired with losing the principles of the diagnosis method.
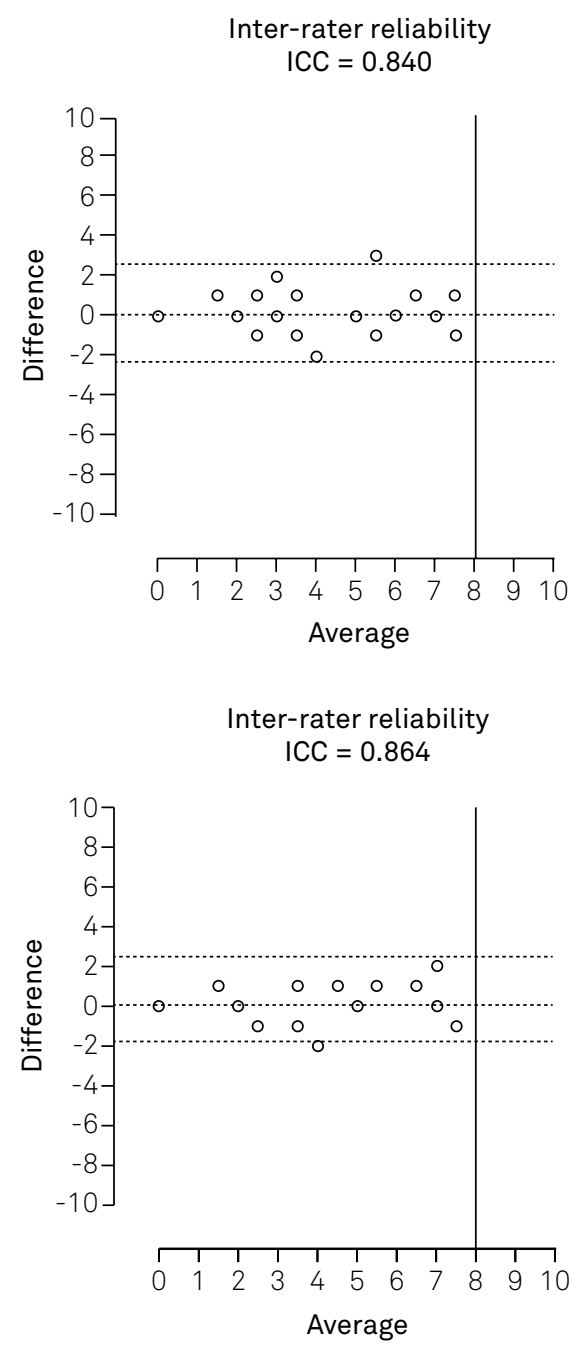

Figure. The bland-altman plots. 
In order to make available the instruments created around the world, the cross-cultural adaptation of the measurement instruments related to human health is essential to use it in other countries beyond the country where it was developed in a safe and equivalent way to original questionnaire ${ }^{13}$.

Nowadays, the DSPN is diagnosed by mean of clinic signals and information obtained from many complementary exams demanding time and procedures to conclude the diagnosis. Then, a unique instrument fast and easy-to-apply would be helpful in the everyday clinical work. The MNSIBrazil can suggest DSPN diagnosis by a set of clear points in the questionnaire and simple physical examination to compose a score system by which we can define objectively if the patient may have or not DSPN.

The Portuguese language is spoken by approximately 240 million of people around the world and the number of published articles by Brazilian researchers and Brazilian researcher's citations has been progressively increased ${ }^{18}$.

The MNSI-Brazil version did not need specific transcultural changes in the application forms; however few adaptations in the text from the introduction (how to use) had to be made to improve the Brazilian Portuguese comprehension. The activities demanding in the questionnaire are quite similar between English and Portuguese as native language people. The Brazilian raters affirmed that the MNSI is a simple, fast and easy-to-apply test performing it in around three minutes. The Brazilian experience confirme the point of view from the specialists who used the original version of the MNSI ${ }^{9,19,20}$.

We tested the MNSI-Brazil in a sample composed by patients who schooling at least 7 years and were able to read and write well. This reflected an efficiency to perform the self-administered part of the MNSI-Brazil that was observed in a maximum of the 3 minutes to respond. Probablely, less years of schooling could change the time to perform it; however we do not have a sample with participants who schooling less than 7 years to confirm this hypothesis.

Studies recording electrical activity in the peripheral nerve are considered the gold-standard method to detect and diagnose the DSPN, even regarding their technical characteristics to evaluate the nervous fibers function in an accurate and precise way. Although electrophysiological studies be the best option to diagnose DSPN, they are expensive and, for this reason, must not be the initial tool to screening; nerve conduction studies must be recommended after the clinical approach, by which the MSNI-Brazil can provide additional information to the therapeutical decision-taking,10,11,19.

The MNSI-Brazil reveals that our sample presented few signals to conclude a neuropathy diagnosis as observed in our results showing just two subjects scored near from the minimum to be considered a suggestion of DSPN. Although the reliability had demonstrated excellent repeatability, we had a sample without patients presenting several suggestion of DSPN, once we had recruited them from healthy services which were giving care to prevent DSPN.

The ICC values showed high inter-rater $(\mathrm{ICC}=0.840)$ and test-retest (ICC $=0.864$ ) reliabilities which were considered excellent $^{21}$, showing an agreement between measures and supporting the use of the MNSI-Brazil for the evaluation of patients with diabete mellitus (Figure). The bland-altman plots (Figure) allows us to observe a magnitude of error absent (zero), very close to zero or no more than 2 points for inter-rater and test-retest analysis. Psychometrical studies pointing to be understandable to find a small error caused by sources issued by performance, concentration, learning, distraction and others ${ }^{22,23}$.

At the end, the results showed evidence to support the use of the MNSI-Brazil with repeated measures acceptable to suggest this instrument among the health professionals dealing with the DSPN in Brazil.

In conclusion, the Brazilian version of Michigan Neuropathy Screening Instrument (MNSI-Brazil) did not show great semantics, linguistics ou cultural discrepances or diferences which could suggest any restraints for Brazilian people with diabetes mellitus. The translation and cross-cultural adaptation process to Portuguese language obtained success following the methodological norms suggested and internationally accepted. Excellent reliability and internal consistency were found, making the MNSI-Brazil a useful instrument to evaluate the peripheral neuropathy signs and symptoms in Brazilians with diabetes mellitus.

\section{References}

1. Boulton AJ, Malik RA, Arezzo JC, Sosenko JM. Diabetic somatic neuropathies. Diabetes Care. 2004;27(6):1458-86. doi:10.2337/diacare.27.6.1458

2. Boulton AJ, VinikAl, Arezzo JC, Bril V, Feldman EL, Freeman R et al. Diabetic neuropathies: a statement by the American Diabetes Association. Diabetes Care. 2005;28(4):956-62. doi:10.2337/diacare.28.4.956

3. Tsapas A, Liakos A, Paschos P, Karagiannis T, Bekiari E, Tentolouris $\mathrm{N}$ et al. A simple plaster for screening for diabetic neuropathy: a diagnostic test accuracy systematic review and meta-analysis. Metabolism. 2014;63(4):584-92. doi:10.1016/j.metabol.2013.11.019

4. Dyck PJ, Davies JL, Wilson DM, Service FJ, Melton LJ 3rd, O’Brien PC. Risk factors for severity of diabetic polyneuropathy: intensive longitudinal assessment of the Rochester Diabetic Neuropathy Study cohort. Diabetes Care. 1999;22(9):1479-86. doi:10.2337/diacare.22.9.1479

5. Tesfaye S, Chaturvedi N, Eaton SE, Ward JD, Manes C, IonescuTirgoviste $\mathrm{C}$ et al. Vascular risk factors and diabetic neuropathy. $\mathrm{N}$ Engl J Med. 2005;352(4):341-50. doi:10.1056/NEJMoa032782

6. Rubio JA, Aragón-Sánchez J, Jiménez S, Guadalix G, Albarracín A, Salido $\mathrm{C}$ et al. Reducing major lower extremity amputations after the introduction of a multidisciplinary team for the diabetic foot. Int J Low Extrem Wounds., 2014;13(1):22-6. doi:10.1177/1534734614521234

7. Kasznicki J. Advances in the diagnosis and management of diabetic distal symmetric polyneuropathy. Arch Med Sci. 2014;10(2):345-54. doi:10.5114/aoms.2014.42588 
8. American Diabetes Association. Standards of medical care in diabetes--2012. Diabetes Care. 2012;35 Suppl 1:S11-63. doi:10.2337/dc12-s011

9. Moghtaderi A, Bakhshipour A, Rashidi H. Validation of Michigan neuropathy screening instrument for diabetic peripheral neuropathy. Clin Neurol Neurosurg. 2006;108(5):477-81. doi:10.1016/j. clineuro.2005.08.003

10. Feldman EL, Stevens MJ, Thomas PK, Brown MB, Canal N, Greene DA. A practical two-step quantitative clinical and electrophysiological assessment for the diagnosis and staging of diabetic neuropathy. Diabetes Care. 1994;17(11):1281-9. doi:10.2337/diacare.17.11.1281

11. Lunetta M, Le Moli R, Grasso G, Sangiorgio L. A simplified diagnostic test for ambulatory screening of peripheral diabetic neuropathy. Diabetes Res Clin Pract. 1998;39(3):165-72. doi:10.1016/S0168-8227(98)00005-9

12. Carvalho AB, Garcia JBS, Silva TKm, Ribeiro JVF. [Translation and transcultural adaptation of Pain Quality Assessment Scale (PQAS) to Brazilian version]. Braz J Anesthesiol. 2016;66(1):94-104. Portuguese. doi:10.1016/j.bjan.2013.10.016

13. Beaton DE, Bombardier C, Guillemin F, Ferraz MB. Guidelines for the process of cross-cultural adaptation of self-report measures. Spine. 2000;25(24):3186-91. doi:10.1097/00007632-200012150-00014

14. Folstein MF. Mini-mental state examination: clinical guide. Lutz: Psychological Assessment Resources; 2001.

15. Bertolucci PH, Brucki SM, Campacci SR, Juliano Y. [The MiniMental State Examination in a general population: impact of educational status]. Arq Neuropsiquiatr. 1994;52(1):1-7. Portuguese. doi:10.1590/S0004-282X1994000100001

16. Callaghan BC, Cheng HT, Stables CL, Smith AL, Feldman EL. Diabetic neuropathy: clinical manifestations and current treatments. Lancet Neurol. 2012;11(6):521-34. doi:10.1016/S1474-4422(12)70065-0
17. Weir JP. Quantifying test-retest reliability using the intraclass correlation coefficient and the SEM. J Strength Cond Res. 2005;19(1):231-40. doi:10.1519/15184.1

18. Cunha RA, Costa LO, Hespanhol Junior LC, Pires RS, Kujala UM, Lopes AD. Translation, cross-cultural adaptation, and clinimetric testing of instruments used to assess patients with patellofemoral pain syndrome in the Brazilian population. J Orthop Sports Phys Ther. 2013;43(5):332-9. doi:10.2519/jospt.2013.4228

19. Mete T, Aydin Y, Saka M, Yavuz HC, Bilen S, Yalcin Y et al. Comparison of efficiencies of michigan neuropathy screening instrument, neurothesiometer, and electromyography for diagnosis of diabetic neuropathy. Int J Endocrinol. 2013;2013:821745. doi:10.1155/2013/821745

20. Herman WH, Pop-Busui R, Braffett BH, Martin CL, Cleary PA, Albers JW et al. Use of the Michigan Neuropathy Screening Instrument as a measure of distal symmetrical peripheral neuropathy in Type 1 diabetes: results from the diabetes control and complications trial/ epidemiology of diabetes interventions and complications. Diabet Med. 2012;29(7):937-44. doi:10.1111/j.1464-5491.2012.03644.x

21. George DM. SPSS for Windows step by step: a simple guide and reference: 11.0 update. 4th ed. Boston: Allyn \& Bacon; 2003.

22. Boyd LA, Vidoni ED, Wessel BD. Motor learning after stroke: is skill acquisition a prerequisite for contralesional neuroplastic change? Neurosci Lett. 2010;482(1):p. 21-5. doi:10.1016/j.neulet.2010.06.082

23. Zhang Y, Ting RZ, Lam MH, Lam SP, Yeung RO, Nan H et al. Measuring depression with CES-D in Chinese patients with type 2 diabetes: the validity and its comparison to PHQ-9. BMC Psychiatry. 2015;15(1):198. doi:10.1186/s12888-015-0580-0 